\title{
EL ATENEO DE LA JUVENTUD. SUS PROPUESTAS Y SU PAPEL COMO EDUCADORES
}

\author{
Ernesto Guadarrama Navarro*
}

RESUMEN: El objetivo de este artículo es realizar una breve revisión sobre las principales contribuciones del Ateneo de la juventud, así como la influencia que este grupo de pensadores tuvo en la educación mexicana. Puesto que Antonio Caso y José Vasconcelos son las figuras más representativas, nos concentraremos en sus ideas, analizando su validez actual y sus posibles errores. La principal propuesta del presente trabajo es señalar la importancia que tiene establecer una estrecha relación entre la filosofía y la educación.

PALABRAS ClAVE: Ateneo de la Juventud, educación, filosofía, Antonio Caso, José Vasconcelos.
ABSTRACT: This article's objective is to give a brief summary of the Mexican Youth Athenaeum's main contributions as well as their influence on Mexican education. Since Antonio Caso y José Vasconcelos are most prominent representatives of this movement, we will focus on their ideas analyzing their current validity and possible mistakes. Our main goal is to emphasize the importance of establishing a close relationship between philosophy and education.

KEYWORDS: Mexican Youth Athenaeum, education, philosophy, Antonio Caso, José Vasconcelos.

RECEPCIÓN: 16 de noviembre de 2010.

ACEPTACIÓN: 06 de agosto de 2013.

* Universidad Católica de Lovaina. 


\section{EL ATENEO DE LA JUVENTUD. SUS PROPUESTAS Y SU PAPEL COMO EDUCADORES}

$\mathrm{Un}_{\mathrm{n}}$

no de los movimientos intelectuales más destacados del siglo pasado es, sin duda, el del Ateneo de la Juventud, cuya labor por promover la cultura en sus diversas manifestaciones y su ímpetu por impulsar la educación en México terminó por influir en el desarrollo de la revolución, que tendría lugar un par de años después de que el Ateneo se constituyera como asociación civil. ${ }^{1}$

${ }^{1}$ El Ateneo no fue el único o el más importante de los grupos intelectuales surgidos en México a lo largo del siglo Xx; baste recordar las grandes aportaciones de otros grupos, como el Hiperión o Los contemporáneos. En el presente ensayo no se pretende poner al Ateneo por encima de otras agrupaciones, o sugerir de forma alguna que éste posea mayor importancia: simplemente, se toma como ejemplo para defender algunas tesis sobre la relación entre la filosofía y la educación que el lector encontrará a lo largo del trabajo.
Los miembros del Ateneo, entre los que cabe destacar a Antonio Caso, José Vasconcelos, Alfonso Reyes y Pedro Henríquez Ureña, se oponían, por un lado, a la calma y pasividad del clima intelectual que vivía México en esa época, y, por otro, a la influencia del positivismo que entendía a la naturaleza como constituida por un duro sistema causal. La influencia del positivismo no fue por completo abandonada, pues éste quería una reforma educativa para México; proponía la libertad de pensamiento y quería un nuevo orden, en el que la religión no paralizara el progreso intelectual y la formación de nuevas ideas. ${ }^{2}$ Podría

${ }^{2}$ A este respecto, $c f r$. Leopoldo Zea, El positivismo en México, 1968, México, FCE, en especial, $\$ 21-23$. 
decirse que tanto los ateneístas como los positivistas mexicanos querían lo mismo: la libertad de pensamiento y el progreso de México. La diferencia estaba en las concepciones filosóficas y en el cómo se conseguirían dichos objetivos.

En otras palabras, no eran los propósitos del positivismo contra lo que se revelaban los miembros del Ateneo, sino contra aquellas ideas que más bien habrían de entorpecer dichos propósitos. Así, contra la interpretación positivista, que reducían a la ciencia y a la filosofía a un saber técnico, los ateneístas se preocuparon por la moral y la cultura, siendo la segunda el instrumento que ayudaría a fortalecer a la primera. Para ello, procuraron nunca perder de vista la realidad social en la que se encontraban.

Apelaban a la indeterminación de la existencia, tanto la de la materia inerte como la de su organización más compleja, que es el hombre. ${ }^{3}$ Para esto, tomaron como base la obra de Bergson principalmente, pues él consideraba que la evolución no es un simple desarrollo que obedece a una cadena causal necesaria, sino un desenvolvimiento que inventa a cada paso formas y contenidos.

Conviene hacer un breve paréntesis, para aclarar un poco las ideas de Bergson que tuvieron influencia en

${ }^{3}$ Cfr. Antonio Caso et al., Conferencias del ateneo, 2000, México, UNAM, p. 62. los ateneístas. ${ }^{4}$ En un principio, Bergson estuvo sumamente influenciado por Spencer, sin embargo, se distanció de este autor al considerar que el evolucionismo que proponía resultaba insuficiente para explicar los fenómenos de la vida y la evolución. Esta insuficiencia era resultado del modelo cientificista con el que se pretendía explicar todo; dicho modelo operaba solamente con conceptos abstractos para los cuales era imposible captar el carácter moviente de la realidad; por lo tanto, era necesario atenerse a la intuición, pues de otro modo dicho carácter moviente se perdería al ser sumido en conceptos estáticos. La vida, el tiempo y la evolución, no podían verse reducidos a las fórmulas con las que se pretendía aprehenderlos. $^{5}$

El filósofo francés definió a la intuición como el equilibrio entre instinto e inteligencia. La inteligencia es la facultad de pensamiento abs-

${ }^{4}$ En este breve paréntesis no se pretende exponer de forma sistemática el pensamiento de Bergson, sino solamente aquellas ideas que fueron fundamentales para los pensadores del Ateneo; en La Evolución creadora las expone de manera más concisa y sistemática. Para un tratamiento detallado sobre el tema de la evolución y el tiempo en este filósofo francés, se puede consultar mi artículo "La experiencia del tiempo", en Alexandre Pomposo, La traza del tiempo. Consideraciones filosóficas sobre la temporalidad, 2011, México, Universidad del Claustro de Sor Juana.

5 "El pensamiento más vivo se helará en la fórmula que lo expresa", Henri Bergson, La evolución creadora, 2007, Buenos Aires, Cactus, p. 141. 
tracto en la que se generan conceptos e hipótesis; gracias a ella, el hombre es capaz de elaborar herramientas para la vida diaria. ${ }^{6}$ El instinto, por el contrario, se ocupa de las cosas materiales, de lo dado a los sentidos, y organiza las cosas de que dispone para servir a sus fines; el conocimiento que él obtiene y la forma en que opera son inconscientes. La inteligencia es insuficiente para comprender el devenir de la vida, porque solamente puede operar con conceptos estáticos, lo que hace que lo moviente escape de sus manos; el instinto, aunque guarda dentro de sí el impulso vital, se encuentra incapacitado para explicar este impulso. Por ello, es necesaria una labor en conjunto, pues "hay cosas que sólo la inteligencia es capaz de buscar, pero que, por si misma, no hallará jamás. Sólo el instinto hallaría esas cosas; pero él jamás las buscará". ${ }^{7}$ La intuición, entonces, conserva el impulso vital del instinto, se atiene a lo dado, con lo cual capta el movimiento de lo real; al mismo tiempo, es consciente de sí misma y capaz de reflexionar sobre las cosas con las que opera. ${ }^{8}$ El carácter esencial de la vida es el de la creación de nuevas formas, lo cual quiere decir que se encuentra en perpetuo movi-

${ }^{6}$ Cfr. ibid., pp. 151-2 y 161.

${ }^{7}$ Ibid., p. 163 (cursivas mías).

${ }^{8}$ Cfr. ibid., pp. 186-7. miento, mismo que es espontáneo e impredecible. Ningún modelo cientificista -incluido por supuesto el evolucionismo de Spencer-, podría ser suficiente para explicar el fenómeno de la vida.

Los ateneístas, tomando como base lo anterior, tenían un marcado impulso por el cambio y la innovación, por abandonar las formas rígidas de conocimiento que el positivismo pretendía establecer y, en su lugar, colocar nuevos paradigmas de educación. Les parecía chocante pensar que la evolución se daba mecánicamente; en oposición, la idea de una invención permanente de las estructuras de la realidad les daba el campo ilimitado que, como educadores, necesitaban. En este sentido, Henríquez Ureña proponía que el cambio, ya fuera en la moral, en la cultura o en la educación, dependía del empeño de los hombres y su afán de perfeccionamiento, por lo que no podía desarrollarse de forma mecánica. ${ }^{9}$

Antonio Caso, por su parte, consideraba que la existencia se dividía en tres vetas: la existencia como economía, que es utilitaria e instrumentalista y pretende un mayor provecho por un mínimo de esfuerzo; la existencia como desinterés, que apela a contemplar la vida como una experiencia estética, en la que no se per-

${ }^{9}$ Cfr. Caso, op. cit., p. 161. 
siguen fines prácticos, sino que se vive como un fin es sí misma; y por último, la existencia como caridad, que, en las antípodas de la vida económica, ofrece un máximo de sacrificio por un mínimo de provecho, es decir, que el hombre se dona a sí mismo para el prójimo. ${ }^{10}$ Para Caso, el gobierno porfirista entendía a la existencia solamente como economía, por lo que el egoísmo inherente a tal concepción de la vida infectaba todo el conocimiento positivista de la época. Vasconcelos se esforzó en reformar esa visión. Se pronunció en contra de tal mezquindad, que presentaba a la humanidad como perversa y confusa; a este respecto, dice: "no sólo hay la realidad, existe también la voluntad que no se conforma y exige el bien. Los valores de la conciencia son una realidad superior que puede y debe dominar el simple caos de los hechos". ${ }^{11}$ Con esta afirmación, Vasconcelos reclama la necesidad de imponer al espíritu sobre los acontecimientos para generar los cambios necesarios. ${ }^{12}$

Tanto Vasconcelos como Caso postularon los valores artísticos, la experiencia estética como un modo de

${ }^{10} \mathrm{Cfr}$. Antonio Caso, La existencia como economía, como desinterés y como caridad, 1989, México, FCE.

${ }^{11}$ José Vasconcelos, Ulises Criollo, 1982, México, FCE, p. 348.

${ }^{12}$ Cfr. Abelardo Villegas, Pensamiento mexicano en el siglo XX, 1993, México, FCE, p. 44. conocer que, por dejar fuera a la teleología y por no contemplar a los objetos solamente en función de su utilidad, podía describirlos tal y como son, es decir, que el desinterés del arte conducía a conocer mejor las cosas que el método científico, al cual calificaban de abstracto y utilitarista. La esencia de las cosas no sería develada nunca por la razón, sino por un impulso emocional, mismo que constituye el dato primario de toda la existencia. ${ }^{13}$ A esto, Caso agrega: "la verdad suprema no está en la inteligencia, sino en la acción". ${ }^{14}$ Sugiere que la búsqueda de la verdad nunca arrojará resultados si dejamos de actuar y nos conformamos con un mero intelectualismo abstracto; al impulso emocional debe agregarse una incansable labor. Es la razón por la que Vasconcelos solía invitar a sus alumnos a abandonar sus "torres de marfil", pues los sabios, intelectuales y artistas tenían la tarea de ayudar a los hombres a mejorar su condición de vida. ${ }^{15}$ Esta sería la característica del período espiritual o estético de la humanidad, un período en que lo que reina no es la razón y el intelectualismo, sino que se buscará la verdad en el sentimiento creador y la belleza,

${ }^{13}$ Cfr. José Vasconcelos, La raza cósmica, Heredia, 1999, Fundación UNA, pp. 53-54.

${ }^{14}$ Caso, op. cit., p. 118.

${ }^{15}$ Cfr. Villegas, op. cit., p. 51. 
pues lo que nace del sentimiento es certero. ${ }^{16}$

Estas ideas llevaron a ambos ateneístas a formular sus propias utopías. Vasconcelos pensaba que llegaría un día en que se perderían las diferencias, en que todas las razas se unirían para formar una nueva, que combinara las virtudes de todas las anteriores: la raza cósmica. Ésta sería superior, no por oprimir o pasar por encima de las demás razas, sino por unificar los mejores aspectos de cada una. ${ }^{17} \mathrm{El}$ predominio de la raza cósmica sería resultado del eclecticismo, no de la discriminación. Sus rasgos definitorios estarían en su espíritu, no en las características físicas; de ahí el conocido lema que Vasconcelos puso a la Universidad Nacional Autónoma de México. Dicha raza tendría que nacer en América, por ser tierra fértil, poseedora de todos los recursos necesarios y en la cual se ha dado desde hace mucho tiempo el mestizaje:

En el suelo de América hallará término la dispersión, allí se consumará la unidad por el triunfo del amor fecundo, y la superación de todas las estirpes. [...] Los pueblos llamados latinos, por haber sido más fieles a su misión divina de América, son los p. 53.

${ }^{16}$ Cfr. Vasconcelos, La raza cósmica, op. cit., ${ }^{17}$ Cfr. ibid., p. 78. llamados a consumarla. Y tal fidelidad al oculto designio es la garantía de nuestro triunfo. ${ }^{18}$

Vasconcelos pensaba que México necesitaba transformaciones sociales para conseguir un mayor bienestar. Estas transformaciones solamente serían posibles siempre que se pusieran en marcha las utopías, bajo la condición de que tales debían obedecer a un impulso desinteresado. Poner en marcha a las utopías era educar, enseñar: serían las más importantes tareas del filósofo. Por esto, nuestro autor llevó sus ideales revolucionarios de los campos de batalla a las aulas, a la enseñanza más que a la labor política, aunque participó en ella activamente.

Para Antonio Caso, la universalidad no tenía por qué implicar una unión de razas, pero sí tenía que tomar en cuenta los puntos de vista de todas, ya que no existe ninguna privilegiada, que importe sobre las demás y por la cual se pierda de vista al resto de la humanidad. ${ }^{19}$ Decía que los hombres tenían una esencia y era menester para todos desplegarla. Consideraba que esa esencia primordial era desarrollar valores para mejorar la calidad de vida y la convivencia social. De hecho, para este

${ }^{18}$ Op. cit., p. 31.

${ }^{19}$ En esto se diferencia de Vasconcelos que, como se mencionaba anteriormente, privilegiaba a los americanos. 
pensador, la sociedad era un cúmulo de relaciones interpersonales, que tiene como finalidad el perfeccionamiento, mediante la educación, de los hombres. Esto llevaría a que dichas relaciones estuvieran basadas en el amor y la caridad, entendidas en sentido cristiano. La educación que hiciera posible esto tenía que ser integral, abarcar la metafísica, la ciencia, la ética, la axiología y sobre todo la estética; la ética era de suma importancia porque guiaría al hombre a los valores supremos; la estética, porque, como se ha mencionado, lleva al hombre a actuar desinteresadamente, además de que es la intuición estética la facultad que distingue al ser humano. ${ }^{20}$ Asimismo, los educadores tenían que tener presente la libertad; su tarea no era solamente impartir datos, sino contribuir a la formación de las personas, permitiendo siempre el desarrollo individual y particular de su personalidad.

Caso propugnaba que la tarea fundamental del Estado era la de impartir esa educación integral, garantizarla, consiguiendo así el perfeccionamiento de las personas, sin restringir nunca la libertad. Así, afirma que el Estado: "ha de garantizar a cada quien la posibilidad de existir, conforme a su esencia, conforme a

\footnotetext{
${ }^{20}$ Antonio Caso, Estética. Obras completas, 1971, México, UNAM, vol. V, p. 77.
}

su modo de ser, dentro del respeto a los demás, que poseen también el propio derecho de existir conforme a su esencia". ${ }^{21}$ Por ello, Caso se pronuncia en contra de los Estados totalitarios y de cualquier régimen que quisiera imponer una ideología, que ignorara a las comunidades o tratara de imputar un tipo de personalidad como la única correcta. Una de las críticas que lanza al régimen porfirista es precisamente la de considerar que el Estado posee un poder absoluto, que incluye decidir qué es lo que conviene en todo momento a los individuos.

Caso consideraba que era posible hacer un cambio radical en el Estado, que lograra que el acento se pusiera en la difusión de la cultura y no en la coacción. Creyó, al igual que Vasconcelos, que la lucha para conseguir este objetivo se daba en las aulas, aunque Caso se ocupó más en este sentido, pues en Vasconcelos se puede observar una mayor preocupación por la política. ${ }^{22}$

Cabe mencionar, también, que Caso concebía el desarrollo de la ciencia, de la filosofía y de la educación siempre dependiente de Dios, pues era él quien daba las pautas, quien nos

${ }^{21}$ Antonio Caso, La persona humana y el Estado totalitario. Obras completas, 1975, México, UNAM, t. VIII, p. 125.

${ }^{22}$ Cfr. Ramos, Samuel, Historia de la filosofia en México, México, UNAM, 1993, p. 156. 
colocaba en la realidad social en la que vivimos, por lo que, sin tomarlo en cuenta y sin tener presente la idea de salvación, resultaría imposible conseguir la organización necesaria de la cultura. En esto se ve claramente como la filosofía de Caso tenía como base el pensamiento cristiano y el sentimiento religioso de la vida. ${ }^{23}$

A estas utopías podemos poner algunas objeciones. En la propuesta de la raza cósmica apreciamos que, aunque se hable de unificación, de una síntesis de razas en la que ninguna sobresale de otra, Vasconcelos privilegia la condición de los americanos, principalmente por su territorio, con lo cual se corre el riesgo de que la propuesta de este filósofo se convierta en el mismo nacionalismo contra el que se pronunciaba. Si bien no podemos poner objeción alguna a sus ataques contra el racismo, sí podemos afirmar que Vasconcelos yerra al atacar de manera directa, incluso despreciar en algunas partes de su obra, a lo que él llama la raza anglosajona; ${ }^{24}$ aunado a esto, aunque se opone al racismo, sigue hablando de jerarquías de

${ }^{23}$ Sin embargo, aunque el pensamiento de Caso era predominantemente cristiano, apelaba por la libertad de culto, ya que el sentimiento religioso esta determinado por la fe, y no hay fe alguna que tenga un alcance universal. A este respecto $C f$ r. Rosa Krauze, La filosofia de Antonio Caso, 1990, México, UNAM, p. 53.

${ }^{24}$ Cfr. José Vasconcelos, La raza cósmica, op. cit., pp. 33-5. razas, considerando que los indios y los negros superan a los blancos. ${ }^{25}$ Sin embargo, podemos decir sin empacho que su idea de tomar lo encomiable de cada una de las razas y adaptarlo a nuestra realidad concreta es algo positivo, que contribuye al desarrollo del pensamiento. Lo que debe dejarse de lado es la idea de que hay razas superiores e inferiores.

La propuesta de la educación como motor del cambio de Caso parece muy pertinente, el problema es que, de fondo, ubica a la religión:

Sin propósito de salvación, sin Dios, la cultura no se organiza en su armonía esencial. Dios es el reino de los fines y el centro de los valores. No porque el humanismo científico creó la máquina, ni porque la filosofía y la ciencia formaron la economía moderna, deja de revestir un sentido perenne el factor que integra la personalidad. ${ }^{26}$

Considero que un pensamiento que proponga a la libertad como fundamental para la educación no debe dar tal importancia a la religión, pues eso excluiría a quienes no poseen ni profesan ninguna fe. Si se entiende a la religión como necesaria para el desarrollo de la personalidad, se es-

${ }^{25}$ Cfr. ibid., pp. 60-1.

${ }^{26}$ Antonio Caso, La pesona humana ..., op. cit., p. 100 . 
taría coartando en parte la libre formación de la misma, ya que se tendría que asumir que no puede integrarse por completo sin creer en Dios. Por otra parte, su propuesta de hacer del Estado un defensor de la educación y la libertad, aunque no tiene en principio ninguna contradicción, hoy en día nos suena más utópica que nunca, pues la historia ha demostrado que, por lo general, quienes ejercen el poder tratan de limitar la autonomía y educar de modo que su régimen parezca el mejor posible. Ese énfasis en la promoción cultural y en la libertad que proponía Caso, aunque debería estar respaldado por el Estado, debe realizarse independientemente de éste.

Algunas de las propuestas de los pensadores del Ateneo son irrealizables; no obstante, otras encontraron su lugar de concreción en las escuelas. Vasconcelos, como rector de la Universidad Nacional Autónoma de México, más que trabajar en ella, se encargó de reestructurarla para que fuese la Universidad la que trabajara por y para el pueblo. Como secretario de Educación Pública comenzó un programa de edición de libros de texto gratuitos y de intercambios culturales con intelectuales y artistas de otros países. También se encargó de la construcción de bibliotecas y edificios que servían para la difusión de la cultura. Antonio Caso tuvo el puesto de director de la Escuela Nacional Preparatoria, rector y secretario de la Universidad Nacional, director de la Facultad de Filosofía y Letras y miembro fundador del Colegio Nacional. Desde estos puestos defendió siempre la libertad de cátedra, de expresión y luchó por la autonomía de la Universidad. Sus ideas sobre la necesidad de hacer una filosofía que no se desentendiera de la realidad en la que se elabora, tendrían eco en la obra de Samuel Ramos y Leopoldo Zea, por mencionar algunos. ${ }^{27}$

Salta a la vista, por lo anterior, que el lugar de la acción, misma que es inherente a la búsqueda de la verdad que proponían los ateneístas, donde obtuvo resultados su labor de mejorar a los hombres y, por último, el único lugar en el que fue posible que sus utopías, en mayor o menor medida, se pusieran en marcha, fue en las escuelas. Conviene que entendamos a la escuela en sentido amplio, es decir, no como el edificio en el que se imparten clases, de forma pública o privada, sino cualquier lugar en el que una persona se dedica a instruir a otros. Debemos tener presente que la enseñanza no queda reducida a su forma académica, puede darse en

${ }^{27}$ Aunque sería sumamente interesante de desarrollar, por el momento queda fuera de los límites del presente trabajo especificar las ideas de los ateneístas que fueron retomadas por sus discípulos. 
distintos lugares, de formas diversas. no contribuye con el bienestar del Lo que debe enfatizarse es que sola- pueblo y la violencia se torna común, mente la educación permitirá los cam- solamente la labor de los educadores bios sociales que necesitamos. El Es- sentará las bases para la renovación tado, cada vez con mayor contundende la cultura. cia, se muestra no sólo incompetente, Por lo tanto, si se pretende un camsino desinteresado en mejorar las condiciones educativas, razón por la cual los pedagogos y demás profesionales de la educación tienen que redoblar esfuerzos, así como estrechar lazos para que se den los cambios sociales que necesitamos. En una sociedad en la que el gobierno bio y si se quiere que el discurso filosófico contribuya a un progreso de la realidad social en la que nos encontramos, los filósofos no deben dejar de lado su papel como educadores, pues allí, posiblemente, las utopías dejen de ser tales y se conviertan en proyectos realizables. 